\title{
INVENTARIO E ESTUDO DE INFRAESTRUTURAS TRADICIONAIS DE CARÁCTER HIDRÁULICO-INDUSTRIAL EN GALICIA
}

Roberto Arias Sánchez

Olalla Mosquera Barreiro

Augas de Galicia. Consellería de Infraestruturas

e Mobilidade. Xunta de Galicia

Laura M. Garrido Fernández

ICEACSA Consultores, S. L. U.

Jorge Núñez Ares

AIN Active S. L.

DOI: 10.17075/pvpcr.2021.005 



\section{INTRODUCIÓN}

As infraestruturas hidráulicas de carácter industrial existentes ao longo de todos os ríos de Galicia conforman un patrimonio de indubidable valor nos aspectos etnográfico e histórico-cultural. Cómpre salientar a súa importancia tanto desde o punto de vista cuantitativo, polo número de instalacións existentes, como cualitativo, con base en aspectos ben arquitectónicos, ben históricos ou relacionados coa enxeñaría hidráulica.

Neste marco, pretendeuse desenvolver un traballo que permitise a identificación, inventario, caracterización e posterior definición de actuacións para a posta en valor e enriquecemento do patrimonio que conforman estas instalacións e, paralelamente, dos ríos e, en xeral, a contorna na que se enmarcan, dando cumprimento, por tanto, ao obxectivo sinalado de conservar e mellorar o patrimonio natural fluvial.

$\mathrm{Na}$ área xeográfica galega, as construcións tradicionais para o aproveitamento dos recursos hídricos ou as instalacións daquelas industrias dependentes da forza dos cursos de auga constitúen os mellores exemplos para entender a continuidade entre arquitectura e territorio que caracteriza a paisaxe agraria preindustrial de Galicia.

A continuación, indícanse os traballos realizados para o inventariado e estudo das infraestruturas hidráulicas.

\section{INVENTARIO DE INFRAESTRUTURAS HIDRÁULICAS TRADICIONAIS}

\subsection{Inventario a partir de fontes documentais}

Realizouse un baleirado documental de diversas fontes de información para a elaboración dun inventario inicial.

\subsubsection{Recursos bibliográficos}

Unha vez consultada toda a bibliografía existente relacionada coas infraestruturas hidráulicas tradicionais de carácter industrial, incluíronse no estudo obras de referencia pola súa importancia na caracterización e análise de enxeños hidráulicos. 


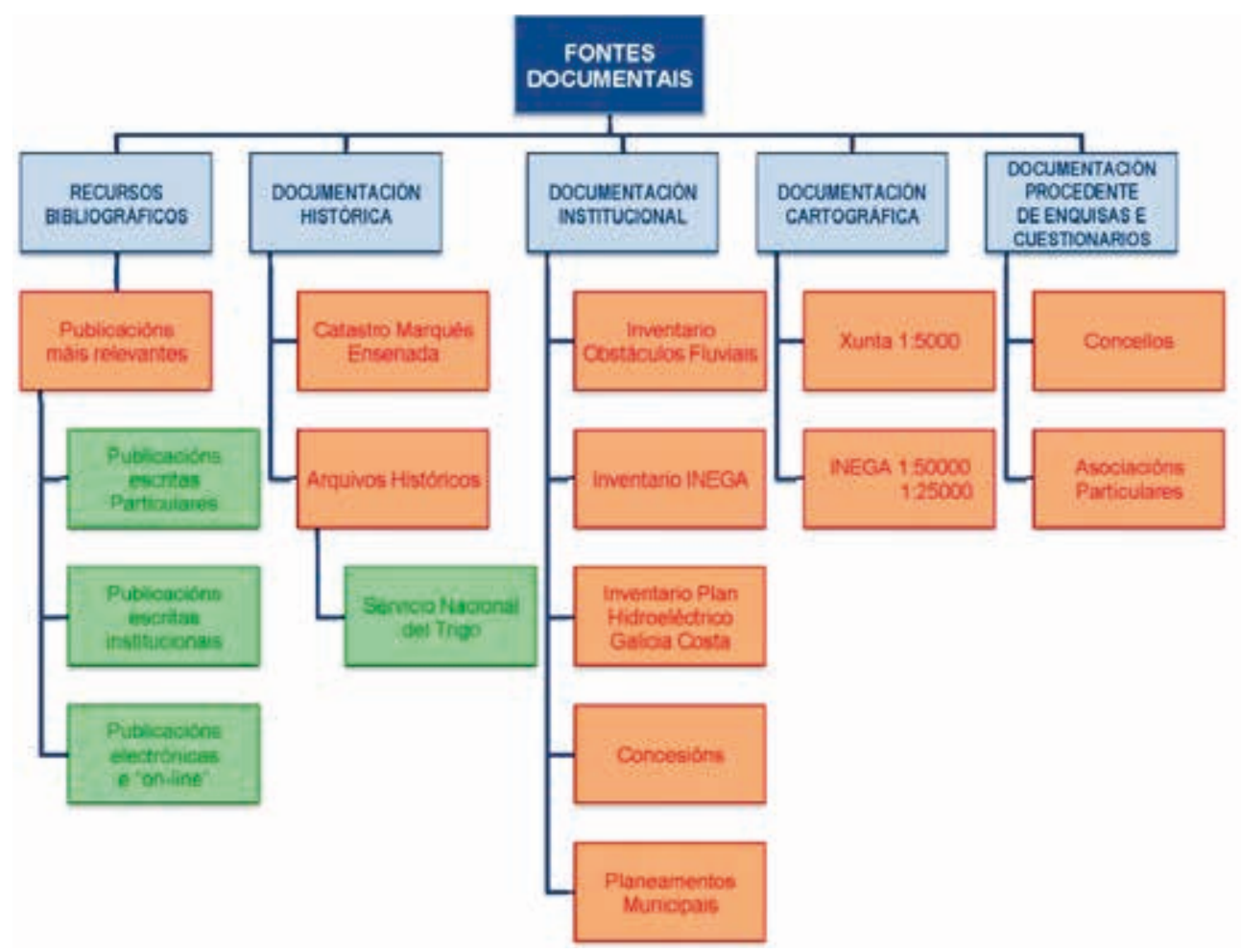

Figura 1. Esquema das fontes documentais consultadas

\subsubsection{Documentación histórica}

2.1.2.1. Catastro del Marqués de la Ensenada (s. XVIII)

Respuestas Generales del Catastro del Marqués de la Ensenada constitúe a máis antiga e exhaustiva enquisa dispoñible sobre as poboacións da coroa de Castela a mediados do século XVIII. Consta de 40 preguntas, pero para o presente traballo a que interesa é a número 17 , onde se pedía información sobre os «molinos harineros, o de papel, batanes u otros artefactos en el término». O catastro estrutúrase por provincias e localidades, o que en Galicia corresponde ás parroquias.

O proceso de baleirado do Catastro de Ensenada constou das seguintes fases:

— Primeira fase: recompilación da información. 
- Segunda fase: lectura de toda a documentación existente e posterior elaboración dunha ficha resumo cos datos máis relevantes (localización, tipo de artefacto, tipo de produción...).

- Terceira e última fase: inicio da identificación e adxudicación das parroquias presentes no catastro aos seus concellos actuais.

\begin{tabular}{|l|c|}
\hline \multicolumn{1}{|c|}{ TIPOLOXÍA } & N.* DE ELEMENTOS \\
\hline N. ${ }^{\circ}$ MUÍNÓS & 15263 \\
\hline N.o ACEAS & 16 \\
\hline N.o BATÁNS & 173 \\
\hline N.o PESQUEIRAS & 188 \\
\hline No. MAZOS/FERRARÍAS & 12 \\
\hline N.o SALINAS & 3 \\
\hline
\end{tabular}

Táboa 1. Tipos de enxeños hidráulicos no Catastro de Ensenada

Segundo os resultados obtidos, o Catastro del Marqués de la Ensenada contabiliza para Galicia un total de 15655 infraestruturas hidráulicas.

\subsubsection{Arquivos históricos. Servicio Nacional del Trigo (s. xx)}

A información atopada nos arquivos históricos céntrase nos expedientes do antigo Servicio Nacional del Trigo do Servicio Nacional de Productos Agrarios (SENPA). Todos estes expedientes do SENPA están depositados nos arquivos provinciais dependentes da Xunta de Galicia.

Desde a década de 1940, é obrigatorio solicitar a inscrición dos muínos no SENPA para poder seguir moendo, motivo polo cal se converten na fonte histórica máis importante do século Xx. Para optar á inscrición do muíño, cada propietario tiña que cubrir unha solicitude dirixida ao xefe provincial do SENPA, quen a analizaba e decidía se a autorizaba ou non. Para realizar o baleirado desta fonte histórica, utilizáronse estas solicitudes e as fichas de apertura de expediente de cada muíño.

Segundo os resultados obtidos, o Servicio Nacional del Trigo contabiliza para Galicia un total de 4031 elementos. 


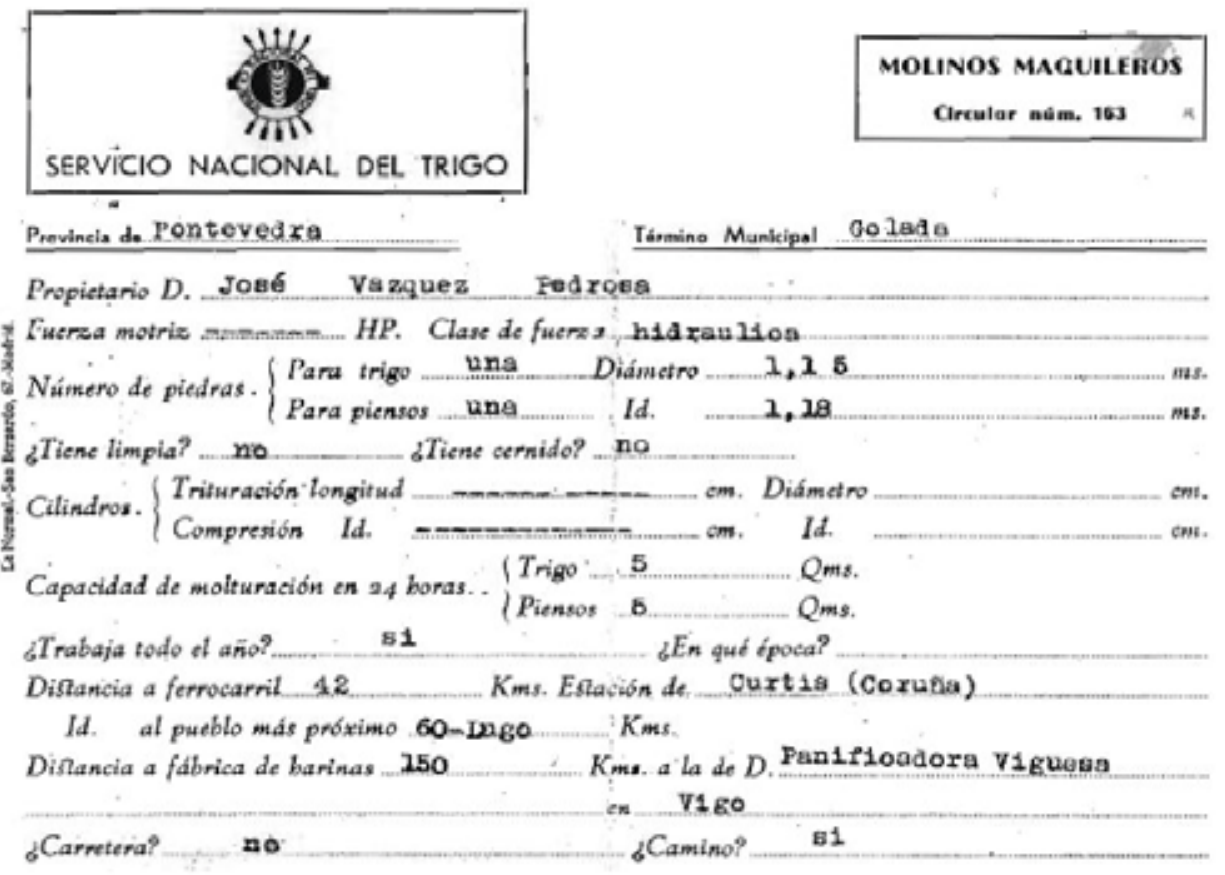

Figura 2. Ficha de exemplo do Servicio Nacional del Trigo dun muíño no concello de Agolada (Pontevedra)

\begin{tabular}{|l|c|}
\hline \multicolumn{1}{|c|}{ PROVINCIA } & N.o DE ELEMENTOS \\
\hline A CORUNA & 1267 \\
\hline LUGO & 1697 \\
\hline OURENSE & 802 \\
\hline PONTEVEDRA & 265 \\
\hline GALICIA & $\mathbf{4 0 3 1}$ \\
\hline
\end{tabular}

Táboa 2. Distribución de elementos por provincia

\subsubsection{Documentación institucional}

2.1.3.1. Inventario de Obstáculos de Especies Fluviais

O Inventario de Obstáculos de Especies Fluviais (presas e azudes) ten como obxectivo determinar que obstáculos poden limitar o remonte do río de migradores. 
Este inventario foi elaborado pola Consellería de Medio Ambiente da Xunta de Galicia.
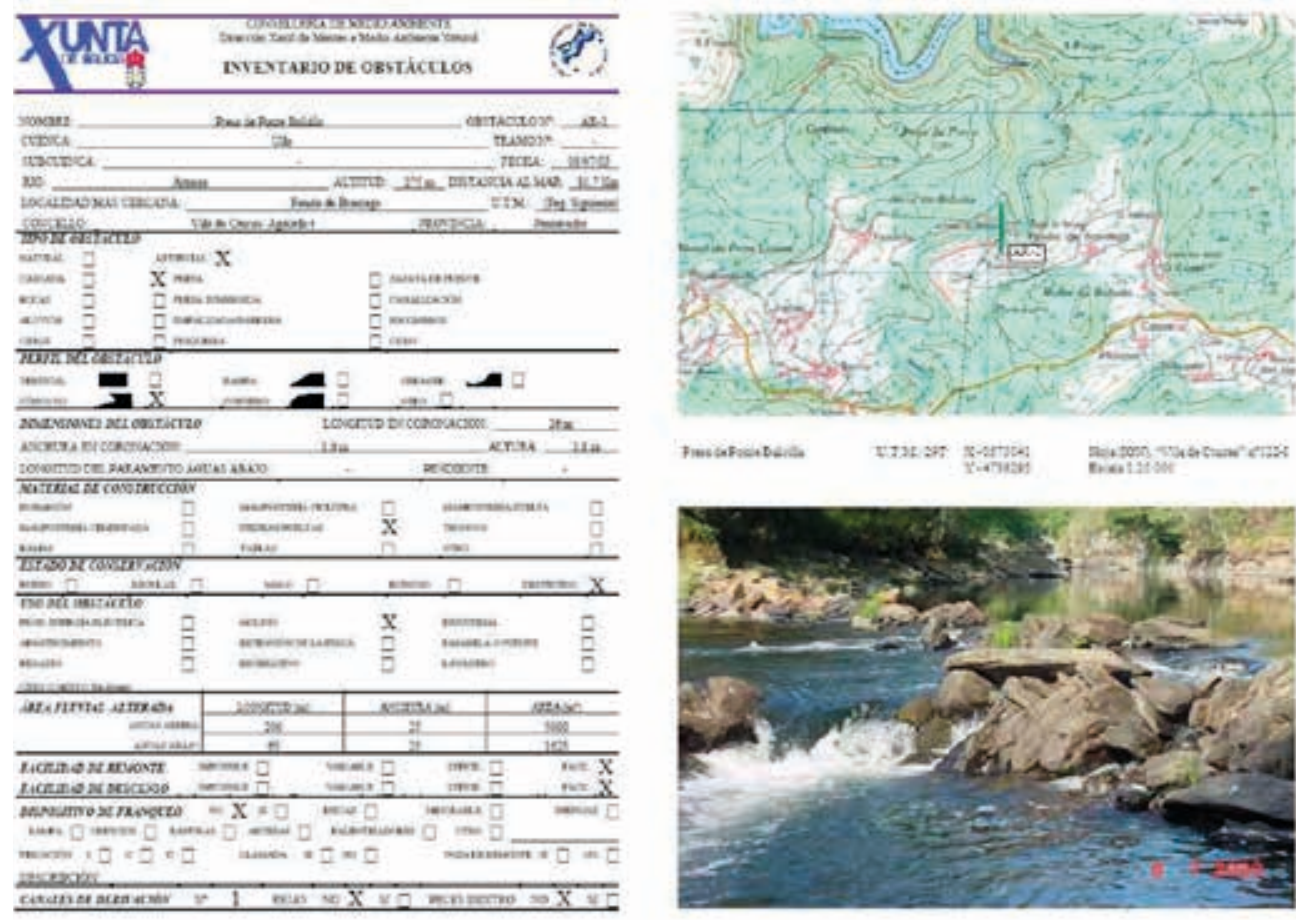

Figura 3. Modelo de ficha e localización dun obstáculo fluvial

\subsubsection{Inventario INEGA}

O Instituto Enerxético de Galicia (INEGA) dispón do Atlas Enerxético de Galicia, ideado como un sistema de información xeográfica das distintas instalacións enerxéticas existentes en Galicia. Esta fonte documental solápase en certa medida co inventario de obstáculos nos datos de presas e azudes; no entanto, a diferenza da fonte anterior, aquí só están recollidos elementos vinculados coa produción de enerxía. 


\begin{tabular}{|l|c|c|c|c|c|}
\hline \multicolumn{1}{|c|}{ PROVINCIA } & $\begin{array}{c}\text { HIDROELÉCTRICAS } \\
\text { MÁIS DE 10 MW }\end{array}$ & $\begin{array}{c}\text { HIDROELÉCTRICAS } \\
\text { MENOS DE 10 MW }\end{array}$ & $\begin{array}{c}\text { CÁMARAS } \\
\text { DE CARGA }\end{array}$ & ENCOROS & $\begin{array}{c}\text { PRESAS/ } \\
\text { AZUDES }\end{array}$ \\
\hline A CORUNA & 7 & 33 & 23 & 21 & 32 \\
\hline LUGO & 6 & 26 & 20 & 12 & 26 \\
\hline OURENSE & 22 & 26 & 24 & 34 & 41 \\
\hline PONTEVEDRA & 4 & 28 & 23 & 10 & 27 \\
\hline GALICIA & $\mathbf{3 9}$ & $\mathbf{1 1 3}$ & $\mathbf{9 0}$ & 77 & $\mathbf{1 2 6}$ \\
\hline
\end{tabular}

Táboa 3. Resumo dos elementos inventariados polo INEGA

\subsubsection{Inventario do Plan Hidroeléctrico Galicia Costa}

Neste plan están recollidas numerosas centrais hidroeléctricas e a información coincide coa do inventario realizado polo INEGA, anteriormente comentado.

\subsubsection{Concesións}

Durante as tarefas de documentación, consultáronse os libros de concesións hidráulicas de Augas de Galicia, que constan de dous volumes de máis de 200 páxinas cada un, con inscricións que van desde finais do século XIX até a década de 1970, ordenados por río e bacía.

O proceso de baleirado tivo dúas etapas:

1. Fotografado dos libros.

2. Baleirado da información.

\begin{tabular}{|l|c|}
\hline \multicolumn{1}{|c|}{ TIPOLOXÍA } & N.o DE ELEMENTOS \\
\hline MUÍNOOS & 509 \\
\hline BATÁNS & 1 \\
\hline FORZA MOTRIZ & 86 \\
\hline SERRAS/SERRADOIROS & 22 \\
\hline CENTRAL ELÉCTRICA & 223 \\
\hline MALLA/CRIBA & 8 \\
\hline PISCIFACTORÍA & 7 \\
\hline OUTROS & 5 \\
\hline
\end{tabular}

Táboa 4. Número de elementos segundo a súa tipoloxía 
Segundo os resultados obtidos, os libros de concesións de Augas de Galicia contabilizan un total de 861 elementos.

\subsubsection{Plans municipais}

A consulta dos plans municipais dos concellos ou, na súa ausencia, das normas subsidiarias provinciais vixentes debería ser unha das fontes máis importantes de catalogación de elementos patrimoniais dada a súa importancia legal en canto á protección do patrimonio local.
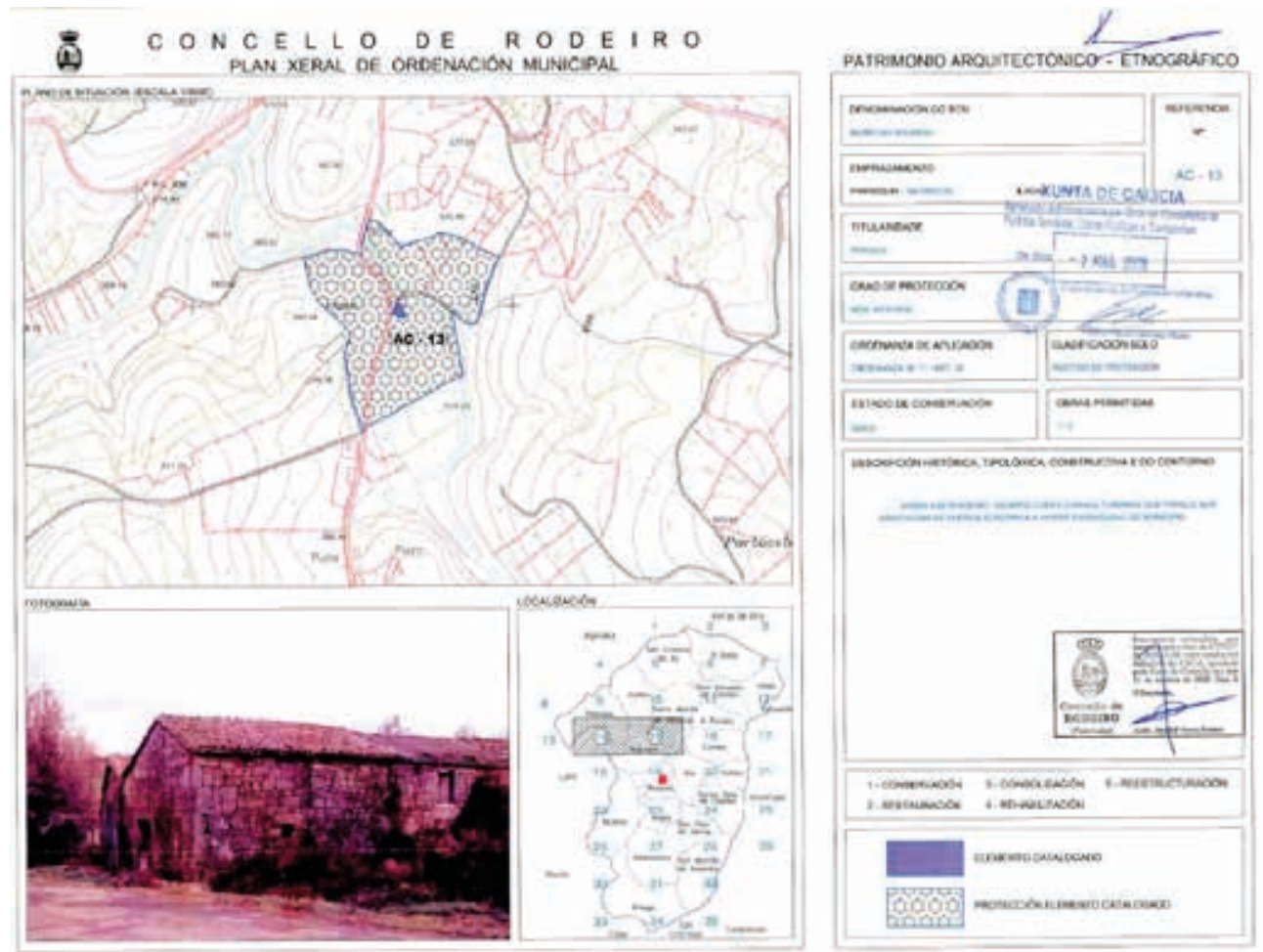

Figura 4. Modelo de ficha-catálogo do plan de Rodeiro (Pontevedra)

Segundo os datos obtidos dos plans vixentes, o número total de elementos recollidos sería de 1525 infraestruturas, distribuídas da seguinte forma: 


\begin{tabular}{|l|c|}
\hline \multicolumn{1}{|c|}{ TIPOLOXÍA } & N. ${ }^{\circ}$ DE ELEMENTOS \\
\hline MUÍNOSOS & 1313 \\
\hline BATÁNS & 4 \\
\hline PRESAS/AZUDES & 1 \\
\hline PESQUEIRAS & 176 \\
\hline SERRADOIROS & 2 \\
\hline MINICENTRAIS & 6 \\
\hline CURTIDOIROS & 14 \\
\hline MAZO/MACHUCO/MOA & 5 \\
\hline FÁBRICA DE PAPEL & 2 \\
\hline CANLE/ACUEDUTO & 2 \\
\hline
\end{tabular}

Táboa 5. Número de elementos segundo a súa tipoloxía

\subsubsection{Documentación cartográfica}

A información cartográfica utilizada para a realización deste estudo foi a dispoñible para todo o territorio galego.

\subsubsection{Cartografía 1:5000 (Xunta de Galicia)}

A elaboración dos planos baseouse no deseño dun Geographic Information System (GIS), no que se definiron os criterios para localizar todos os elementos que puidesen formar parte do patrimonio hidráulico.

O deseño do GIS tivo as seguintes fases:

1. a fase. Depuración cartográfica. Referente ás edificacións, cursos fluviais e rede viaria.

2. ${ }^{a}$ fase. Aplicación das pautas de localización das posibles edificacións que puidesen ser elementos de orixe hidráulica-industrial.

3. ${ }^{\mathrm{a}}$ fase. Codificación dos elementos resultantes.

Obtívose así un plano inicial cuns criterios de localización homoxéneos para toda Galicia.

Segundo os resultados obtidos, a cartografía 1:5000 da Xunta de Galicia contabiliza un total de 15911 elementos. 
INVENTARIO E ESTUDO DE INFRAESTRUTURAS TRADICIONAIS DE CARÁCTER HIDRÁULICO-INDUSTRIAL EN GALICIA

\begin{tabular}{|l|c|}
\hline \multicolumn{1}{|c|}{ PROVINCIA } & N.o DE ELEMENTOS \\
\hline A CORUNAA & 3055 \\
\hline LUGO & 4613 \\
\hline OURENSE & 3784 \\
\hline PONTEVEDRA & 4459 \\
\hline GALICIA & $\mathbf{1 5 9 1 1}$ \\
\hline
\end{tabular}

Táboa 6. Distribución de elementos por provincias

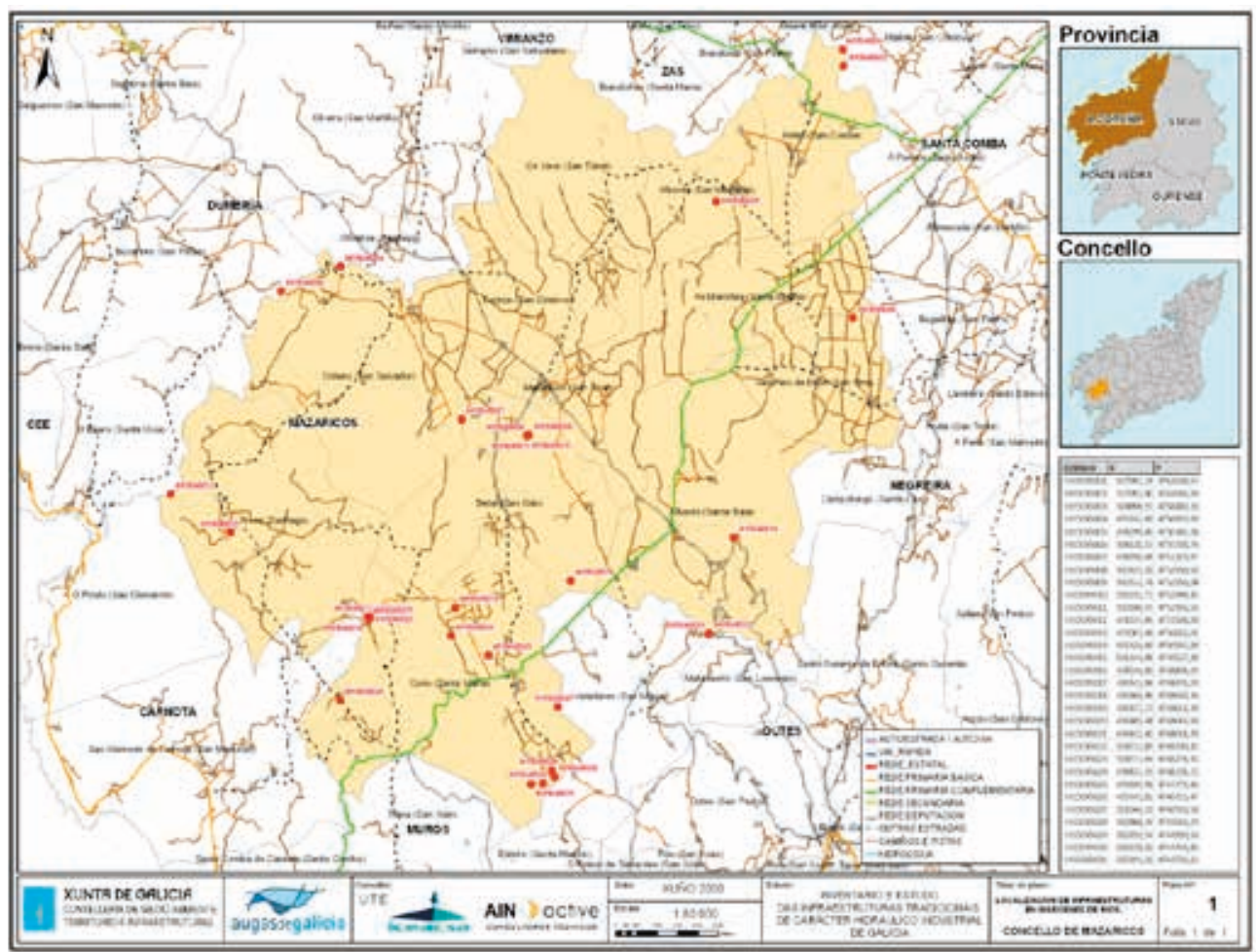

Figura 5. Exemplo de plano base utilizado durante os traballos de recompilación de información

\subsubsection{Cartografía 1:50 000 e 1:25 000 (IGN)}

O mapa topográfico nacional (MTN) a escala 1:25 000 e 1:50 000 do Instituto Xeográfico Nacional (IGN) en formato vectorial e raster é unha das fontes carto- 
gráficas dispoñibles máis importante que existen en España. Nel están representados numerosos muíños hidráulicos. Para realizar o inventario inicial, utilizouse soamente a cartografía a escala 1:25 000, pero tratáronse as dúas fontes por igual para comparar os resultados obtidos.

\begin{tabular}{|l|c|c|}
\hline \multicolumn{1}{|c|}{ PROVINCIA } & $\begin{array}{c}\text { N. } \text { DE ELEMENTOS } \\
\text { DO MTN 25 000 }\end{array}$ & $\begin{array}{c}\text { N.o DE ELEMENTOS } \\
\text { DO MTN 50 000 }\end{array}$ \\
\hline A CORUNA & 2464 & 2348 \\
\hline LUGO & 1096 & 1100 \\
\hline OURENSE & 321 & 337 \\
\hline PONTEVEDRA & 1311 & 1387 \\
\hline GALICIA & $\mathbf{5 1 9 2}$ & $\mathbf{5 1 7 2}$ \\
\hline
\end{tabular}

Táboa 7. Número de elementos segundo a fonte cartográfica

Segundo os resultados obtidos, tanto a cartografía 1:25 000 coma a 1:50 000 do IGN contabilizan un total de 5172 elementos.

2.1.5. Documentación procedente de enquisas e cuestionarios (concellos, organismos privados e particulares)

Para comezar as tarefas de sondaxe de información, confeccionouse un modelo de enquisa que foi enviado aos concellos e outras institucións. $\mathrm{Na}$ enquisa preguntábanse as características xerais do patrimonio hidráulico-industrial existente no seu ámbito territorial.

Con toda a información obtida por medio de enquisas ou pescudas elaborouse unha táboa de 1718 elementos de carácter hidráulico-industrial correspondentes a 53 concellos.

\subsubsection{Elaboración do catálogo previo}

Tras o baleirado documental, procedeuse á elaboración dun catalogo inicial no que se inclúe a información de todas as fontes documentais. A maiores inclúense, aproximadamente, uns 200 elementos recollidos en fontes documentais a través de Internet.

O catálogo estrutúrase da seguinte maneira: 
A. Unha primeira parte resumo, onde se computan todos os elementos obtidos nas diferentes fontes documentais, en cada concello. O número total de infraestruturas hidráulicas de rexistros de infraestruturas documentadas ascende a máis de 30000 .

B. Unha segunda parte daqueles que se recompilou maior información e que pasan a formar parte dun catálogo inicial. Este catálogo está formado por ao redor de 3100 infraestruturas, reflectidas en fichas semellantes á que se amosa a continuación.

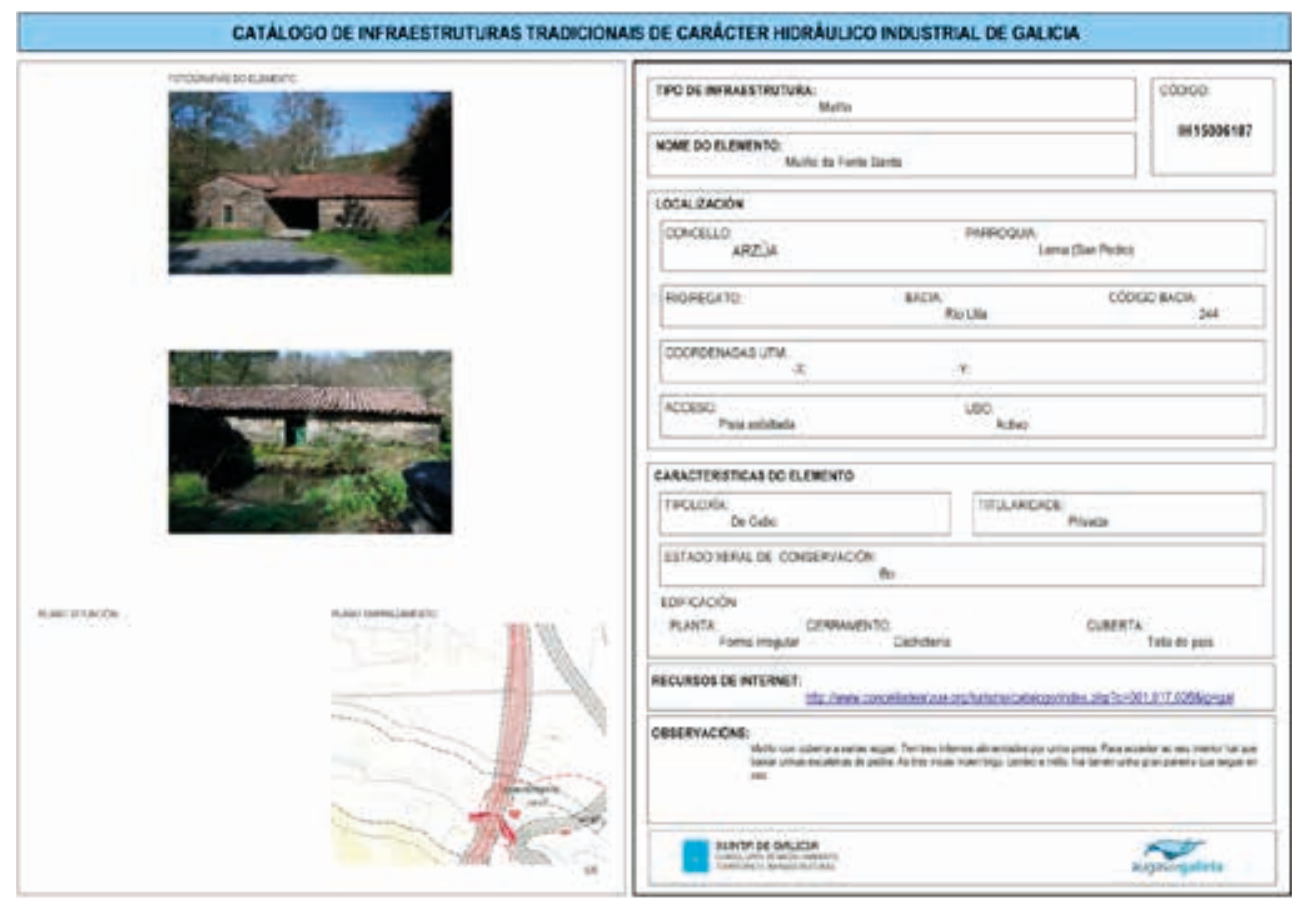

Figura 6. Ficha de exemplo do catálogo previo

\subsection{Inventario a partir de visitas de campo}

A partir das visitas de campo, complétase o inventario inicial extraído das fontes documentais.

A metodoloxía de traballo para a obtención da información destinada á elaboración do novo catálogo foi a seguinte:

- Contacto cos representantes municipais. 
- Localización das infraestruturas máis representativas mediante a información previa das fontes documentais e a existente no propio concello.

Durante a visita de campo, recompílase a seguinte información:

1. Coordenadas de situación

2. Plano de planta

3. Medidas interiores e exteriores

4. Reportaxe fotográfica

Así mesmo, realízase unha acta de visita na que se recollen os elementos visitados, os representantes que van como acompañantes durante esta e unha pequena descrición destes elementos.

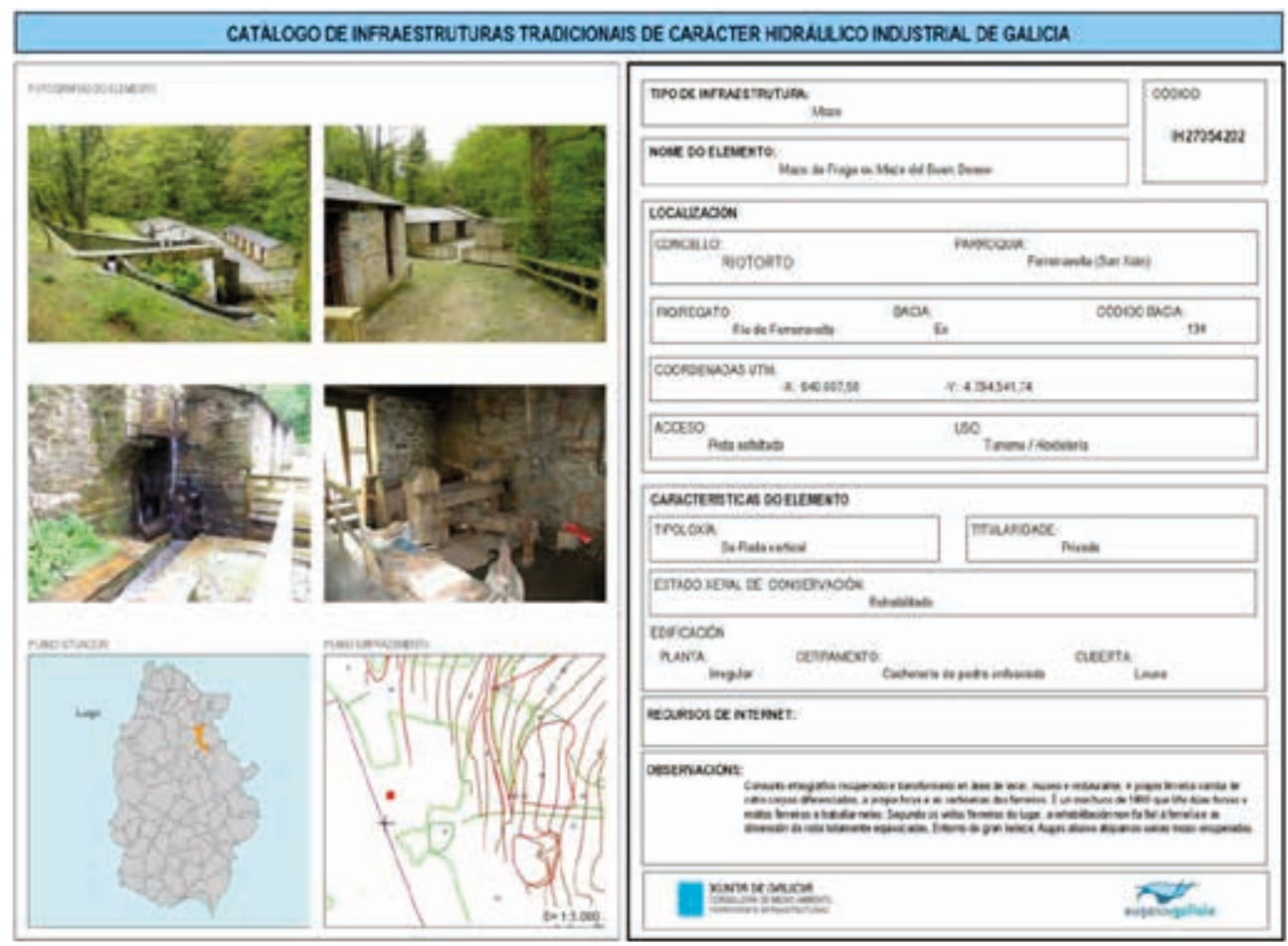

Figura 7. Ficha exemplo de ficha catálogo 


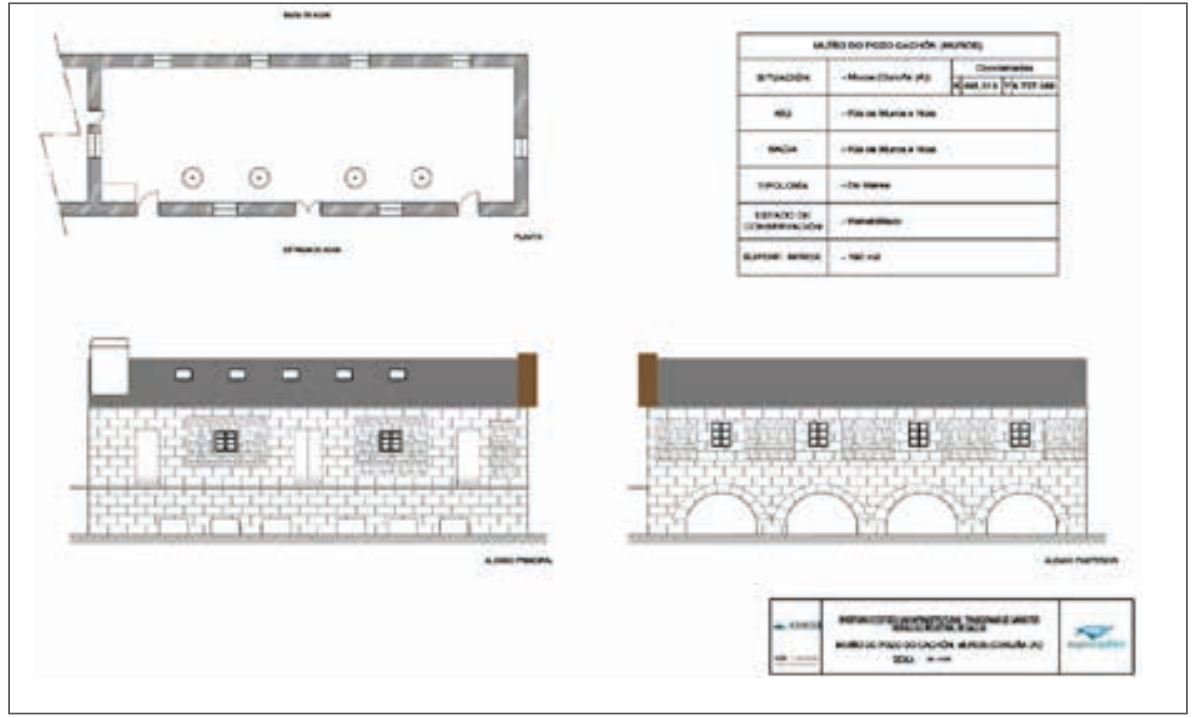

Figura 8. Exemplo de plano

Esta mesma ficha é exportada ao programa Google Earth, que permite acceder a través de imaxes satélite á localización dos distintos elementos.

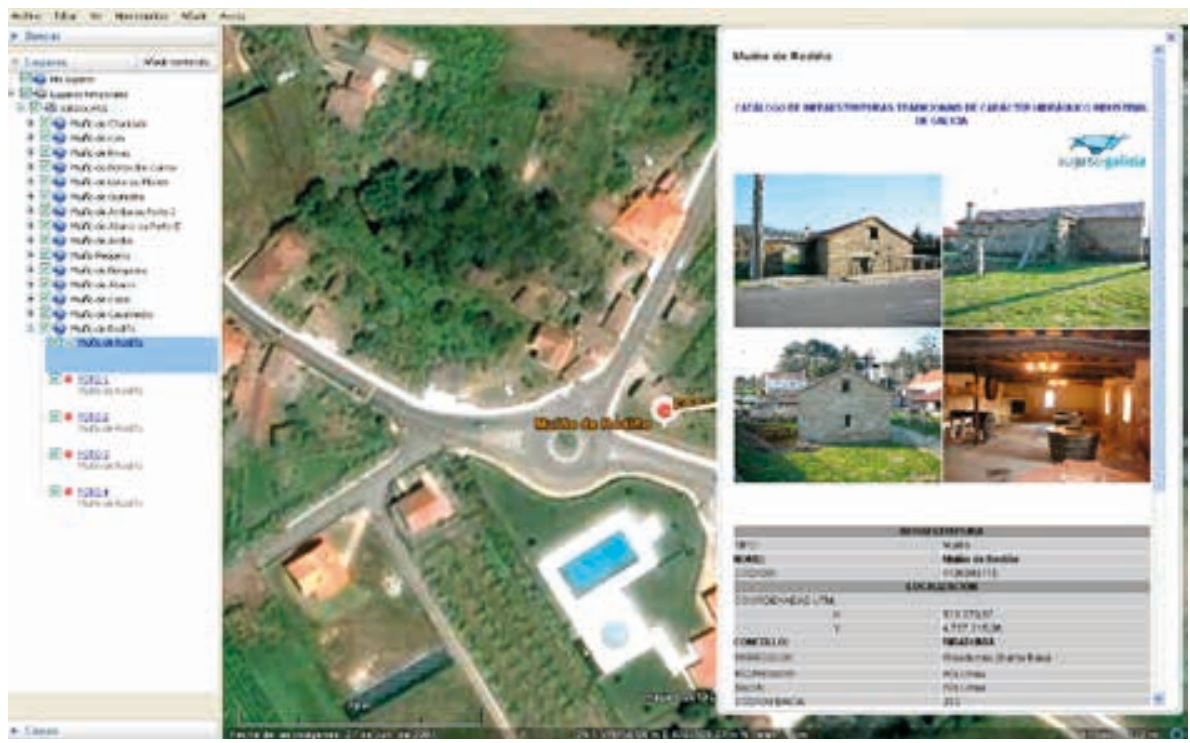

Figura 9. Exemplo de ficha de catálogo en formato Google Earth 
Neste novo inventario, recóllese un total de case 1100 elementos, entre os que se atopan muínos, batáns, mazos, fábricas de papel, fábricas de luz, serradoiros, azudes, presas e pesqueiras.

\begin{tabular}{|l|c|c|c|c|c|c|c|}
\hline \multicolumn{1}{|c|}{ Provincia } & $\begin{array}{c}\text { Muíńos } \\
\text { de río }\end{array}$ & $\begin{array}{c}\text { Muíños } \\
\text { de marea }\end{array}$ & Batáns & Serradoiros & Ferrarías & Pesqueiras & $\begin{array}{c}\text { Mazos/ } \\
\text { machucos }\end{array}$ \\
\hline A CORUNA & 319 & 3 & 3 & 1 & - & - & 2 \\
\hline LUGO & 172 & 1 & 1 & 6 & 3 & 2 & 7 \\
\hline OURENSE & 254 & - & - & 3 & 3 & - & 1 \\
\hline PONTEVEDRA & 215 & 4 & 1 & 5 & - & 3 & - \\
\hline TOTAL & $\mathbf{9 6 0}$ & $\mathbf{8}$ & $\mathbf{5}$ & $\mathbf{1 5}$ & $\mathbf{6}$ & $\mathbf{5}$ & $\mathbf{1 0}$ \\
\hline \multicolumn{1}{|c|}{ Provincia } & $\begin{array}{c}\text { Fábricas } \\
\text { de coiros }\end{array}$ & $\begin{array}{c}\text { Fábricas } \\
\text { de luz }\end{array}$ & $\begin{array}{c}\text { Fábricas } \\
\text { de papel }\end{array}$ & Azudes & $\begin{array}{c}\text { Minicen- } \\
\text { trais/CH }\end{array}$ & Acuedutos & Lavadoiros \\
\hline A CORUNA & 3 & 2 & 2 & 5 & 10 & 2 & 1 \\
\hline LUGO & - & 5 & - & 1 & 4 & - & - \\
\hline OURENSE & 7 & 3 & 2 & 7 & 10 & - & - \\
\hline PONTEVEDRA & - & 1 & - & 3 & 2 & - & - \\
\hline TOTAL & $\mathbf{1 0}$ & $\mathbf{1 1}$ & $\mathbf{4}$ & $\mathbf{1 6}$ & $\mathbf{2 6}$ & $\mathbf{2}$ & $\mathbf{1}$ \\
\hline
\end{tabular}

Táboa 8. Resumo por provincias e tipoloxías

\section{VALORACIÓN DE INFRAESTRUTURAS E SELECCIÓN DAS MÁIS REPRESENTATIVAS}

\subsection{Valoración de infraestruturas inventariadas}

Coa totalidade dos elementos visitados, procedeuse a unha valoración multifactorial baseada en índices numéricos que permitiu coñecer o valor estimado ou patrimonial de cada unha das infraestruturas.

Os aspectos que se tiveron en conta foron os seguintes:

- Singularidade

○ A. Elemento único.

- B. Máxima puntuación, tipoloxía escasamente representada en Galicia. Estes elementos veñen sendo os muíños de marea, os batáns e os machucos, os mazos e demais estruturas relacionadas co traballo do ferro.

○ C. Valor dependendo de se integran conxuntos que maximizan o aproveitamento da auga. 
- Valor arquitectónico

○ A. Edificación:

- Muros: cantaría, perpiaños, cachotaría de pedra etc.

- Cuberta: pedra (lousa, laxes), tella etc.

- Estrutura de madeira: cimbros, correas etc.

- Ocos: portas, ventás etc.

- B. Infraestrutura hidráulica:

- Canles, cubos etc.

A complexa e delicada configuración construtiva do conxunto de cada unha destas instalacións é consecuencia da continuidade entre a arquitectura da instalación hidráulica e a maquinaria que procesa o recurso. Na maioría dos casos, a infraestrutura e a mecánica compoñen unha unidade que comparte técnicas e materiais.

A técnica das solucións vai refinándose progresivamente desde as canles e os muros até as comportas, pas ou rodas, formando unha unidade. Se ben os seus elementos son perfectamente distinguibles, a técnica das súas solucións fainos interdependentes e, polo tanto, ten peso na valoración dos exemplos catalogados, a integridade dos sistemas construtivos tradicionais e o seu nivel de alteración.

Mediante a integración dos datos obtidos do GIS, cada infraestrutura ten unha valoración multifactorial.

\begin{tabular}{|l|c|c|}
\hline \multicolumn{1}{|c|}{ Singularidade } & Estado de conservación (muros, cubertas) & Accesibilidade \\
\hline 5. Elemento único & 5. Bo & 5. Bordo de estrada \\
\hline $\begin{array}{l}\text { 4. Elemento singular no } \\
\text { contorno galego }\end{array}$ & 4. Regular & 4. Pista asfaltada \\
\hline $\begin{array}{l}\text { 3. Elemento singular no } \\
\text { contorno da comarca }\end{array}$ & 3. Presenza de pequenas derrubas & 3. Pista de balastro \\
\hline 2. Elemento común & 2. Grandes danos estruturais & 2. Camiño carro \\
\hline 1. Elemento moi común & 1. Só quedan as cimentacións & 1. Senda de pescadores \\
\hline $\begin{array}{c}\text { Conservación de } \\
\text { elementos mecánicos }\end{array}$ & Presenza de documentación histórica & $\begin{array}{c}\text { Contorno paisaxístico e orixinais/ } \\
\text { funcionalidade medioambiental da } \\
\text { edificación }\end{array}$ \\
\hline 5. Restaurados & 3. Identificación precisa & 5. Parque natural \\
\hline 4. Bo estado & 2. Identificación dubidosa & 4. Zona LIC/Rede Natura 2000 \\
\hline 3. Estado regular & 1. Ausente & 3. Paisaxe tradicional \\
\hline $\begin{array}{l}\text { 2. Deteriorados ou } \\
\text { desaparecidos en parte }\end{array}$ & & 2. Área urbanizada \\
\hline 1. Inexistentes & & 1. Área degradada \\
\hline
\end{tabular}

Táboa 9. Valoración de infraestruturas inventariadas 


\subsection{Selección de infraestruturas de maior representatividade}

Segundo os resultados obtidos na valoración multifactorial, establecemos, de forma ordenada por puntuación, a identificación das infraestruturas de maior representatividade (ver táboa 10).
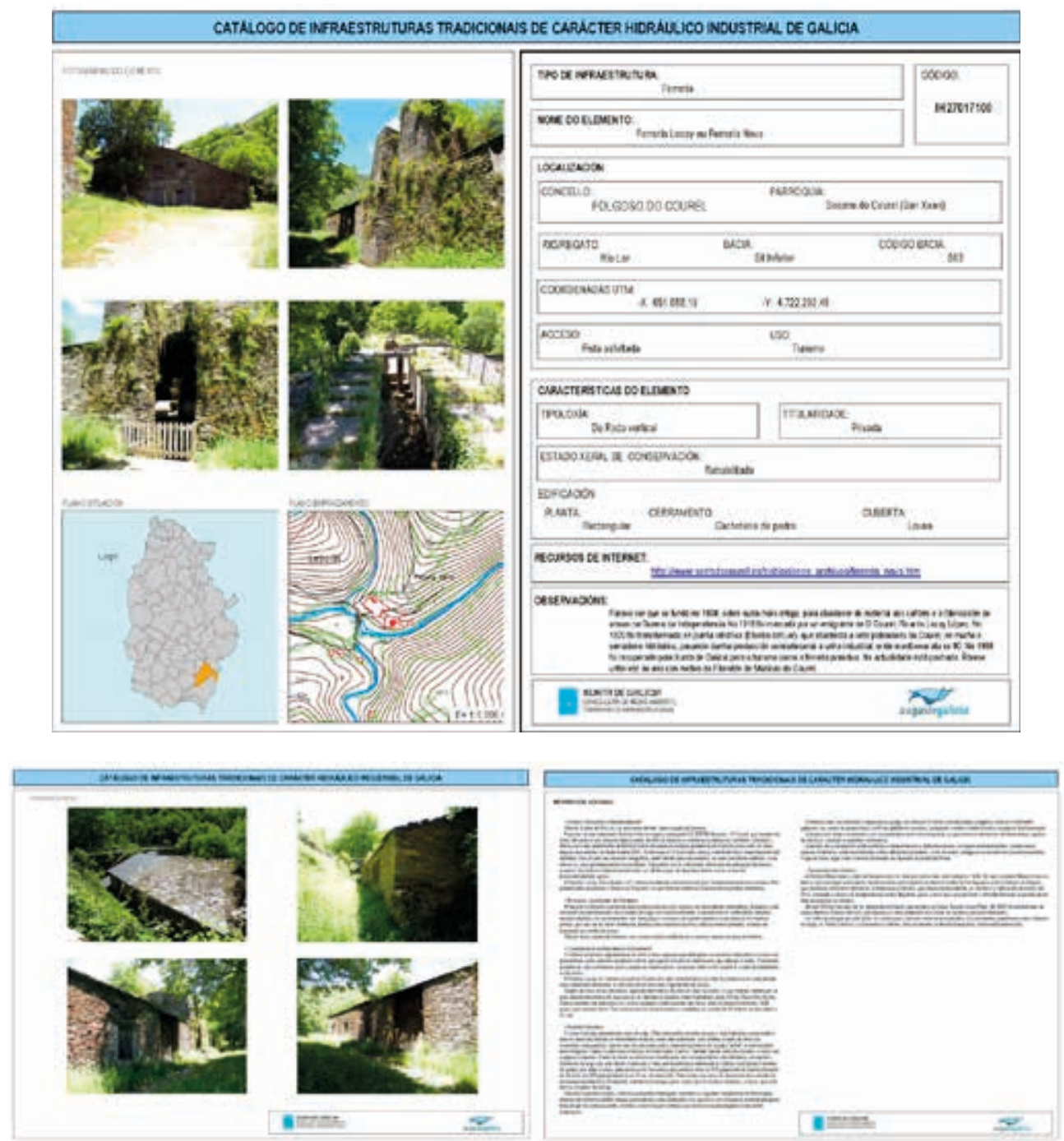

Figura 10. Exemplo de ficha do catálogo das infraestruturas máis representativas 
Esta representación consta dun total de 127 elementos e é unha mostra do patrimonio tradicional de carácter industrial presente nos ríos galegos.

\begin{tabular}{|l|c|c|c|c|c|c|c|}
\hline \multicolumn{1}{|c|}{ Provincia } & $\begin{array}{c}\text { Muínís } \\
\text { de río }\end{array}$ & $\begin{array}{c}\text { Muínos } \\
\text { de marea }\end{array}$ & Batáns & Serradoiros & Ferrarías & Pesqueiras & $\begin{array}{c}\text { Mazos/ } \\
\text { machucos }\end{array}$ \\
\hline A CORUNA & 19 & 3 & 2 & - & - & - & 1 \\
\hline LUGO & 29 & 1 & 1 & - & 2 & 1 & 5 \\
\hline OURENSE & 17 & - & - & - & 1 & - & 1 \\
\hline PONTEVEDRA & 16 & 4 & - & 1 & - & - & - \\
\hline TOTAL & $\mathbf{8 1}$ & $\mathbf{8}$ & $\mathbf{3}$ & $\mathbf{1}$ & $\mathbf{3}$ & $\mathbf{1}$ & $\mathbf{7}$ \\
\hline \multicolumn{1}{|c|}{ Provincia } & $\begin{array}{c}\text { Fábricas } \\
\text { de coiros }\end{array}$ & $\begin{array}{c}\text { Fábricas } \\
\text { de luz }\end{array}$ & $\begin{array}{c}\text { Fábricas } \\
\text { de papel }\end{array}$ & Azudes & $\begin{array}{c}\text { Minicen- } \\
\text { trais/CH }\end{array}$ & Acuedutos & Lavadoiros \\
\hline A CORUNA & 3 & 1 & 2 & 1 & 4 & 1 & 1 \\
\hline LUGO & - & - & - & - & 3 & - & - \\
\hline OURENSE & 3 & - & 2 & - & 1 & - & - \\
\hline PONTEVEDRA & - & 1 & - & - & - & - & - \\
\hline TOTAL & $\mathbf{6}$ & $\mathbf{2}$ & $\mathbf{4}$ & $\mathbf{1}$ & $\mathbf{8}$ & $\mathbf{1}$ & $\mathbf{1}$ \\
\hline
\end{tabular}

Táboa 10. Número de elementos seleccionados (127), fronte ao número total de elementos visitados (1100)

\section{POTENCIALIDADE DE POSTA EN VALOR}

Os 127 elementos de maior representatividade son sometidos a unha análise máis detallada co fin de avaliar as posibilidades e necesidades de actuación para a súa posta en valor.

Cada infraestrutura ten unhas necesidades e características específicas debido á presenza de valores elevados de calidade, singularidade e orixinalidade.

Segundo o estado de conservación da edificación, realizarase unha estimación dos investimentos que cómpre efectuar e da habilitación dos accesos.

Esta análise dos 127 elementos deu lugar a un novo catálogo que define con máis detalle o patrimonio etnográfico, cultural e arquitectónico asociado.

Para a posta en valor das distintas infraestruturas hidráulicas, diferenciaranse:

A. Infraestruturas hidráulicas de pequena dimensión. Sistematización da posta en valor. 
B. Infraestruturas hidráulicas singulares. Para rehabilitalas, será necesario realizar un estudo pormenorizado de cada infraestrutura e das súas posibilidades de uso.

C. Infraestruturas xa rehabilitadas.

Para a posta en valor das 127 infraestruturas, realizouse unha estimación económica na que se tiveron en conta os seguintes aspectos:

— Edificación: muros (limpeza/restauración), carpintaría, cuberta (limpeza/ restauración), estrutura (limpeza/restauración), chan (limpeza/restauración), instalacións (electricidade/abastecemento).

— Infraestrutura hidráulica: canle, cubo.

- Acceso e contorno.

- Difusión cultural.

\section{CONCLUSIÓN}

No presente documento, expóñense de forma resumida os traballos desenvolvidos para a realización dun «Inventario de Infraestruturas Tradicionais de Carácter Hidráulico Industrial en Galicia».

A partir de fontes documentais primeiro e de visitas a todos os concellos galegos despois (en coordinación con eles), foi posible identificar os elementos documentados e, mediante visitas de campo, aqueles que puidesen ser máis significativos en cada un deles.

Deste xeito, nunha primeira fase identificáronse case 30000 rexistros de elementos e elaborouse un catálogo inicial daqueles cuxa documentación era suficiente para incluíla nese catálogo. Nel recóllense preto de 3100 elementos.

Posteriormente, tras a visita de campo, elaborouse un catálogo que recompila os elementos máis significativos de cada concello de Galicia, recollendo neste caso preto de 1100 elementos.

Estes elementos foron estudados para finalmente obter unha relación daqueles que puidesen ter un maior interese. Desta análise resultan 127 elementos, dos cales se fixo un estudo máis detallado e para os que se valoraron cales son as accións necesarias para a súa posta en valor. 


\section{REFERENCIAS BIBLIOGRÁFICAS}

Bande Rodríguez, E. (1997): «El molino de Nuestra Señora de Beariz», en I Jornadas Nacionales sobre Molinología, Sada (A Coruña), Ediciós do Castro, 735-739. (Cadernos do Seminario de Sargadelos; 75).

BAS López, B. (1993): As construccións populares. Un tema de etnografía en Galicia, Sada (A Coruña), Ediciós do Castro. (Cadernos do Seminario de Sargadelos; 44).

BAS López, B. (1997): «Recursos y técnicas en los molinos de Galicia. Una síntesis de las tipologías», en I Jornadas Nacionales sobre Molinología, Sada (A Coruña), Ediciós do Castro, 725-734. (Cadernos do Seminario de Sargadelos; 75).

BAS López, B. (1981): «Consideracións xerais para o estudo dos muínos en Galicia», Cadernos de Estudos Galegos, tomo XXXII, CSIC-Padre Sarmiento, 96-97.

Bas López, B. (1990): «Las primeras menciones de molinos de mareas de Galicia», LLULL, 13, 43-56.

Bas López, B. (1991): Muiños de marés e de vento en Galicia, A Coruña, Fundación Pedro Barrié de la Maza.

Fernández Negral, J. (1997): «Historia y arquitectura de los molinos de un municipio costero: Cedeira (A Coruña)», en I Jornadas Nacionales sobre Molinología, Sada (A Coruña), Ediciós do Castro, 697-712. (Cadernos do Seminario de Sargadelos; 75).

Justino Fernández, J. (1991): Forxas hidráulicas, mazos ou machucos no norte galego, Sada (A Coruña), Ediciós do Castro. (Cadernos do Seminario de Sargadelos; 54).

Lema Suárez, X. M. a / R. Mouzo Lavandeira (2007): O conxunto etnográfico dos batáns e muiños do Mosquetín, na Terra de Soneira. Outros batáns, folóns ou pisóns de España e Portugal, Vimianzo, Seminario de Estudos Comarcais da Costa da Morte.

Llano Cabado, P. De (1980): O muiño de mar de A Seca, Santiago de Compostela, Colexio de Arquitectos de Galicia.

Lores Rosa, X. (1987): Os muiños, Vigo, A Nosa Terra.

López Otero, M. L. (2007): Catalogación do patrimonio etnográfico e natural na beira dos ríos de Boiro, Boiro, Cadernos Culturais, Concello de Boiro.

Pena Graña, A. (1997): «A muiñería industrial de Narón», en Primeras Jornadas Nacionales sobre Molinología, Sada (A Coruña), Ediciós do Castro, 713-723. (Cadernos do Seminario de Sargadelos; 75).

PIÑEIRO, Miguel (2008): Lampreas e pesqueiras, Vigo, Galaxia.

Soutelo VázQuez, R. / A. Varela Sabas (1997): «Los molinos del río Barbantiño», en I Jornadas Nacionales sobre Molinología, Sada (A Coruña), Ediciós do Castro, 683-696. (Cadernos do Seminario de Sargadelos; 75).

Ramiro Barros, J. (1997): Muiños nas terras de Pontevedra, Pontevedra, Deputación Provincial. 